\title{
FLIGHT TESTS FOR THE ASSESSMENT OF TASK PERFORMANCE AND CONTROL ACTIVITY
}

Heinz-Jürgen Pausder and Dieter Hummes Deutsche Forschungs- und Versuchsanstalt für Luft- und Raumfahrt e.V. (DFVLR) Institut für Flugmechanik, Braunschweig, FRG

\section{Abstract}

Helicopter flight tests were conducted to look at the influences of pilot and helicopter system on the performance in NOE-flying. A visual dolphin course was built up. The tests were performed with the helicopters BO 105 and UH-1D. Closely connected with tactical demands the six test pilots' task was to minimize the time and the altitude over the obstacles. The data reduction yields statistical evaluation parameters describing the control activity of the pilots and the achieved task performance. The results are shown in form of evaluation diagrams. Additionally dolphin tests with varied control strategy were performed to get more insight into the influence of control techniques. From these test results recommendations can be derived to emphasize the direct force control and to reduce the collective to pitch crosscoupling for the dolphin.

\section{Introduction}

The military or civil user of a helicopter primarily emphasizes the demand for a successful completion of his special mission. This requirement is an unsufficiently defined basis for the design efforts of a helicopter system. Therefore the need exists to transform tactical demands in standards of technical terminology. With such diagnostic tool the contractor is thus enabled to check the achieved adaptation of the overall requirement of adequate mission performance during the design phase. Once the helicopter has been built, the question about the qualities of the flying characteristics is also asked. If it doesn't meet the mission demands, the question is: Why not? Consequently flying quality specifications should contain technical scales for a quantitative evaluation and they. should set the standards for 1) checking the tactical missions demands, 2) transforming these demands in measurable data, 3) proving the efforts during the design phase, and 4) a quantitative evaluation during the certification phase.

Nevertheless, the specification MIL$\mathrm{H}-8501 \mathrm{~A}^{\mathrm{I}}$ is valid still nowadays. The basis of these requirements was constituted of simulation and flight test results performed in the Fifties. The development in the field of helicopter design which happened during the last two decades has not been taken into consideration. Implementing rotors with non-hinged blades and divergent flying characteristics of the helicopter pointed out that the application of the specifications can yield wrong conclusions. Although the requirements could not be met, acceptable flying qualities have been inferred from pilot evaluations. ${ }^{2}$

As a consequence of these discrepancies several attempts have been made to revise the specifications. The specification MIL$F-83300^{3}$ was published for V/STOL-systems. closely following the structure and format of the specification for conventional aircraft, the different demands of maneuvers are considered by coordinating requirements to three categories of flight phases. MIL-F83300 attempted to include the helicopter systems,but the essential criticism of its application for helicopters implies that the specific problems of helicopter flying qualities and helicopter missions are not taken into account sufficiently.

The application of helicopters are greatly extended. This includes the expansion of mission types, and the specific demands of mission phases. In Fig. 1 typical mission parts are skeletonized as they are presently being discussed in the F.R.G.:

1) Anti tank.

2) Combat rescue.

3) Air to air.

The mission phases can be characterized by the required low altitude above ground and by the flight speed. Demanding of the pilot/helicopter system to use the terrain as cover against exposure and to obtain superiority in direct contact with the enemy high agility is required of helicopter system. Current specifications for flying qualities regarding the demands of such specific missions phases don't exist. Alternatively an assessment of adequate flying characteristics can be performed due to pilot evaluations given in flight or simulation tests. But this approach doesn't get rid of the urgent problem of formulating requirements for flying qualities in parameters. Those can be registered by measurements and can be applied to a certification as evaluation scales. 


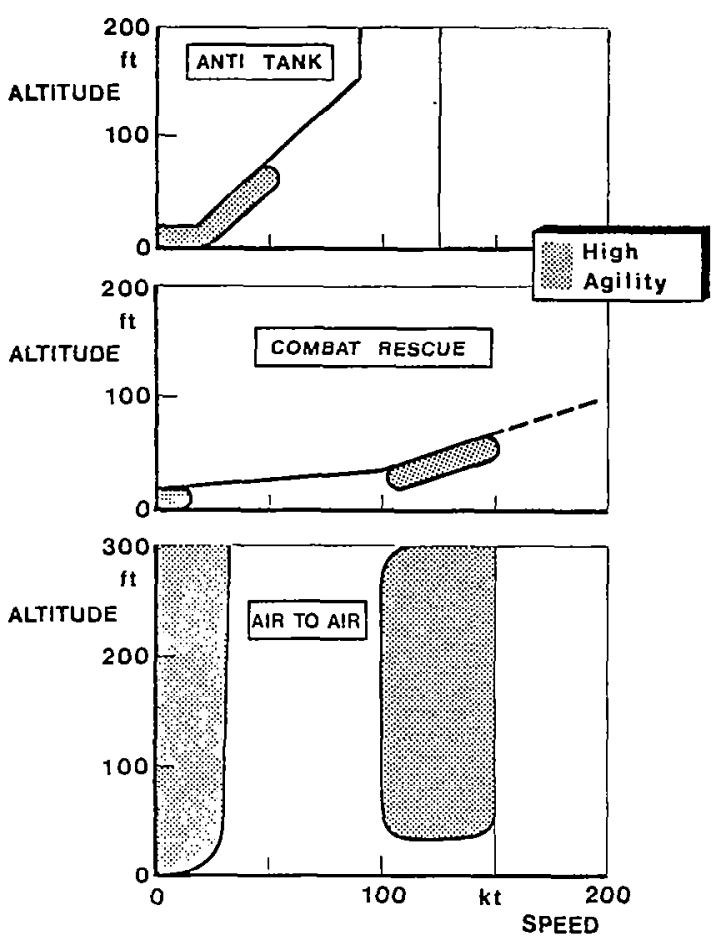

Fig. 1 Helicopter missions

Primarily, the objective of flight mechanical investigations is to constitute a data base for deriving recommendations for flying quality criteria. The different tactical mission demands of today require a mission- and task-oriented adaptation of the evaluation. In several institutions activities exist with this objettive. ${ }^{4}, 5$ At the Institute for Flight Mechanics of the DFVIR a technical approach was also developed with the overall objectives as follows: 1) to investigate task-oriented flying qualities; 2) to constitute a flying qualities data base for the assessment of quantitative requirements for helicopter systems.

\section{DFVLR Evaluation Method}

In this paper a brief review of the DFVLR evaluation method shall be given. More details are presented in Ref. 6. The ulterior motive is the correlation of pilot ratings from flight tests with parameters obtained by a statistical analysis of measured data. The statistical parameters, which include a good correlation with the ratings, are collected in the data base.

Fig. 2 shows the general approach. starting from a given mission, elements are selected which are representative for this mission and which include the demands which are critical for a flight mechanical

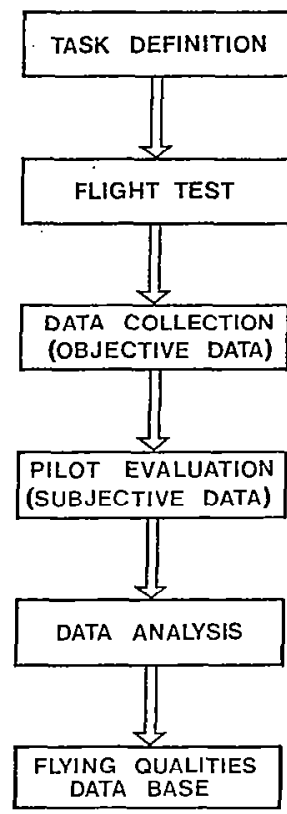

- Selection of mission elements - REPRESENTATIVE
- REPRODUCiBLE - REALISTIC

- variation of test configuratjons - AJC PARAMETERS

- TESIIIG WITH SEVERAL PILOTS

- mfasuring amd timf-sync.Hronized rfcoroing - A/C STATE VARIABLES - PILOT CONTROL MOVEMEETS

Pilot ratings and COANENTS - PILOT STRESS

- TASK PERFOPHAANCE

detajled statistical analysis of

CORRELATION OF STATISTICaL PARAMETERS

WITH SUBJECTIVE DATA

- collection of parmmeters
RELEVANT TO EVALUATION

Fig. 2 Evaluation approach

evaluation. The statistical analysis of the test data calls for a definition of the flight test task that allows a reproducable test performance. This includes clear instructions of task conditions and test objectives for the test pilot. On the other hand, the test conditions should as much as possible correspond to the realistic conditions of the selected mission element. In order to obtain a broad data base, the test configurations are varied. This can be achieved by variation of:

1) Helicopter characteristics.

2) Environmental conditions.

In order to register and eliminate the individuality of the pilots, several pilots should be engaged in the tests.

The following data are measured and recorded: 1) state variables of the helicopter, 2) control inputs of the pilot, and 3) position variables of the helicopter. One test is composed of a number of runs with equal conditions. Additionally the pilot ratings and comments are collected of each test. The applied rating scale corresponds to the Cooper-Harper scale ${ }^{7}$, but it is slightly modified by dividing them into three groups of questions referring to the workload of the pilot, the task performance and the handing qualities of the helicopter. This yields a redundancy of the ratings. By adding the pilot comments the interpretation of the ratings is facilitated more. 


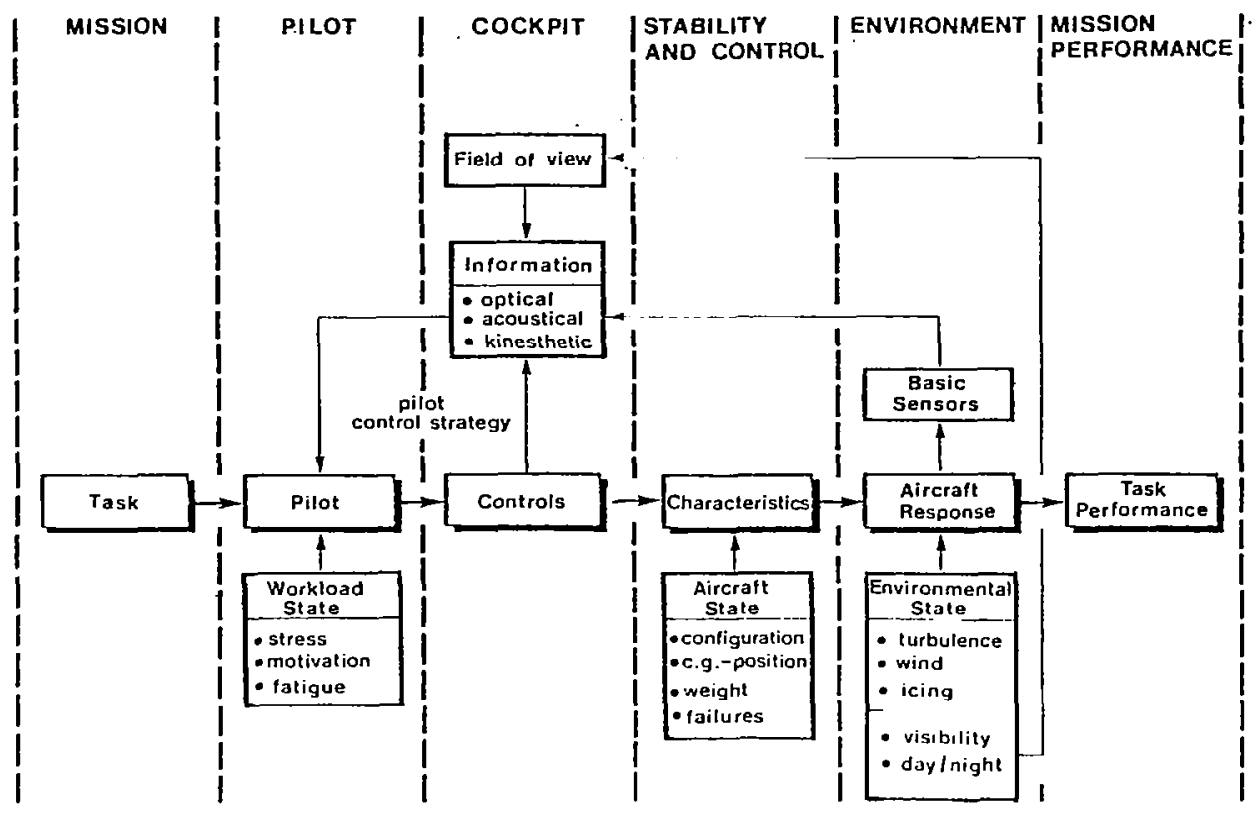

Fig. 3

Factors influencing pilot/helicopter system performance

In a detailed statistical analysis the measured data are then reduced to parameters characterizing the dynamic behaviour of the closed-loop system. By correlating the pilot ratings and comments with the statistical parameters the relevance to the evaluation is being checked. Parameters with high correlation to the ratings are collected in the flying qualities data base.

\section{Influence Factors}

The task performance and the control activity depends on various influences, described in the pilut-in-the-loop diagram of Fig. 3. Proceeding from the defined flight task, the elements of the loop with partly time dependent characteristics are passed through to get the task performance as the result. The main influence factors result form the pilot and the helicopter system.

The pilot transfers the task instructions in a conception of an adequate task performance as reference for the system performance achieved in the test. The human pilot adapts to the task, the characteristics of the helicopter and the subsystems, and the environmental state by means of a control strategy appearing optimal to him. In doing so, he profits his high capability of adaptation. The handiing qualities of the helicopter system represent the limitations for the pilots adaptation. The feedback to the pilot with different types of information includes influences intensifying with extreme environmental states and technically displayed information.

To define the conditions of flight testing and to interpret the test results, those many influence factors have to be taken into consideration. This involves 1) a well defined test task, 2) clear pilot instructions, 3) a qualified selection of test pilots, 4) well defined environmental conditions, and 5) a definition of helicopter state and pilot information.

\section{Doscription of Experiments}

\section{Evaluation Task}

The starting point for the DFVLR studies was the German anti tank mission. This mission includes phases with high portions of precise hovering, quick stop maneuvers and flying near the ground making use of the terrain as a cover. With close reference to the tactical demands, the DFVLR evaluation tasks were defined (Fig. 4 ). First studies were conducted with a hovering tracking task. 8,9

For the dolphin task a course was built with two obstacles, as shown in Fig. 5. The distance between the obstacles was $350 \mathrm{~m}$. The rur starled $200 \mathrm{~m}$ before the first obstacle and ended $200 \mathrm{~m}$ behind the second obstacle. The obstacles had an altitude of $15 \mathrm{~m}$. They were built up as to put the pilot into a - as much as possible - realistic situation which he has to deal with. For safety aspects the last $3 \mathrm{~m}$ are consist of bushes. The centerline of the course is marked on the ground to fa- 

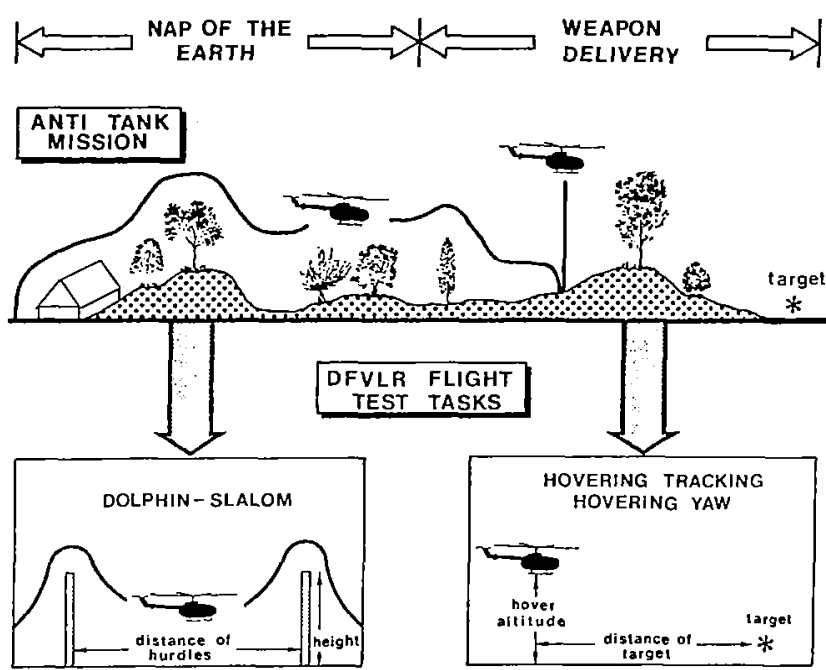

Fig. 4 Definition of evaluation tasks

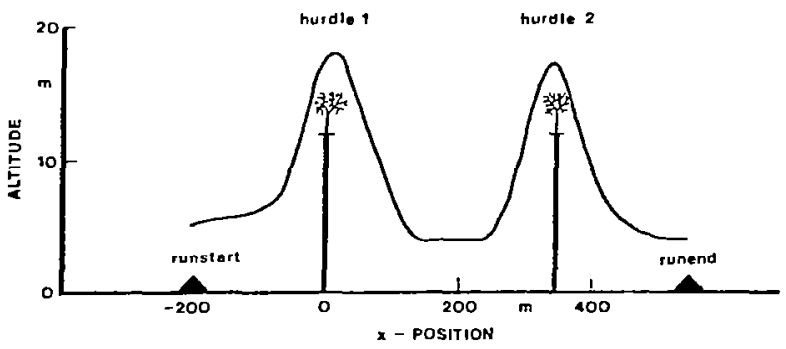

Fig. 5 Dolphin course

cilitate the heading for the pilots. In the dolphin tests, the pilots are instructed to traverse the course while minimizing the time and the altitude over the obstacles. The altitude of entering and finishing the course is $15 \mathrm{ft}$ over ground and the pilots have to align the helicopter on the $15 \mathrm{ft}$ altitude between the obstacles if possible. The speed was defined in the test conditions and had to be flown in the beginning, between the obstacles and at the end of the course. Deviations of heading, lateral position, and bank attitude was to be avoided.

To study the influence of control strategy the task is slightly varied. The pilots have to perform the course at firstwith a control combination of the pilot's concept, secondly with using only stick inputs and thirdly using primarily collective inputs and the longitudinal cyclic for minimizing the pitch attitudes due to coupling.
Filight 'l'ests

The flight tests were conducted with the helicopters BO 105 of the DFVLR and UH-1D of the German Forces Flight Test Center (Fig. 6). Different test configurations were achieved by varying the test parameters speed and gross weight. Table 1 shows the test matrix for the dolphin test with the BO 105 .

Table 1. Test configurations dolphin

\begin{tabular}{ccc}
\hline & \multicolumn{3}{c}{ Gross weight } \\
Speed & $G_{\min }$ & $G_{\max }$ \\
\hline $40 \mathrm{kt}$ & $\mathrm{X}$ & $\mathrm{X}$ \\
$60 \mathrm{kt}$ & $\mathrm{X}$ & $\mathrm{X}$ \\
$80 \mathrm{kt}$ & $\mathrm{X}$ & $\mathrm{X}$ \\
$100 \mathrm{kt}$ & $\mathrm{X}$ & $\mathrm{X}$
\end{tabular}

In order to obtain a broad spectrum of pilot's behaviour, six test pilots were involved ( 3 of the Flight Test Center, 1 of the DFVLR and 2 tactical test pilots of the Army). The control strategy tests were performed with both helicopters and three test pilots. Table 2 reviews the configurations.

Table?. Test configurations control strategy

\begin{tabular}{|c|c|c|c|}
\hline \multirow[b]{2}{*}{ Speed } & \multicolumn{3}{|c|}{ BO $105 / U H-1 D\left(G_{\min }\right)$} \\
\hline & $\begin{array}{l}\text { Comb. } \\
\text { control }\end{array}$ & $\begin{array}{l}\text { Cyclic } \\
\text { control }\end{array}$ & $\begin{array}{l}\text { Collect. } \\
\text { control }\end{array}$ \\
\hline $40 \mathrm{kt}$ & $X$ & $\mathrm{X}$ & $X$ \\
\hline $60 \mathrm{kt}$ & $X$ & $X$ & $\mathrm{X}$ \\
\hline $80 \mathrm{kt}$ & $x$ & $\mathrm{X}$ & $\mathrm{X}$ \\
\hline $100 \mathrm{kt}$ & $X$ & $\mathrm{X}$ & $\mathrm{X}$ \\
\hline
\end{tabular}

The testing procedure was always the same to guarantee reproducable test results. After explaining the objectives the task instructions were given to the pilot. Although all pilots were experienced in NOEflying, sufficient time was given to them to train the colurse. Subsequent $1 \mathrm{y}$, each test was conducted by flying seven isolated runs of the same kind. A quicklook was installed in the ground station to control the training and the test.

\section{Data Acquisition}

After each test, the pilot had to answer a quesiionnaire relating only to the test performed. The questions concerned the 

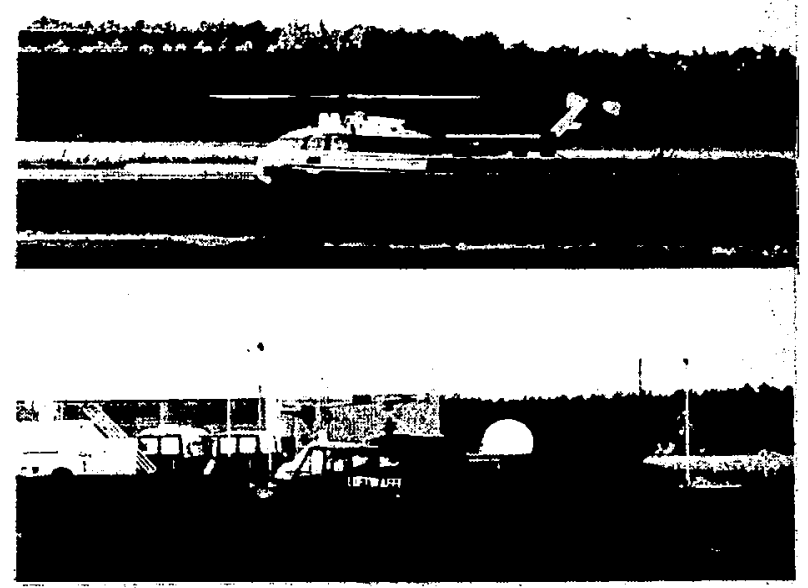

Fig. 6 Test helicopters

pilot workload, the quality of task performance and the handling qualities. In addition to that the pilots commented on the reasons for their ratings. The data acquisition was provided by an analog magnetic tape recording in the ground station. Recorded variables included control inputs, attitudes, rates, accelerations, air speed, altitude, torque and rotor speed. The helicopter position data relativ to the obstacles was measured by a laser position tracking system and was recorded time synchronized with the helicopter state and control data. To register these data in the helicopter and to transmit them to the ground a proprammable multipurpose instrumentation system was used.10 The concept made it possible to reach a quick adaptation to the test technique (helicopter type, direction of flight). The data were digitized online in the ground station and were available for data analyzing, sampled with a frequency of $20 \mathrm{~Hz}$.

\section{Discussion of Dolphin Results}

The pilot ratings of the task performance and handling qualities are compared with the ratings of workload as shown in Fig. 7. There are clear differences of up to three points betwecn the ratings evaluating the handling qualities and the workload with the tendency to give the handling qualities a better rating. Applying the original Cooper-Harper scale a close relation is suggested between the demand on the pilot and the aircraft characteristics.Indeed, the precondition for this assumption is observing exactly a tentatively defined task performance. In more complicated flight tasks as the dolphin, the pilots yield a variation of performing the task. In this way, the ratings for the handling qualities are influenced too. This behaviour also accounts for the good
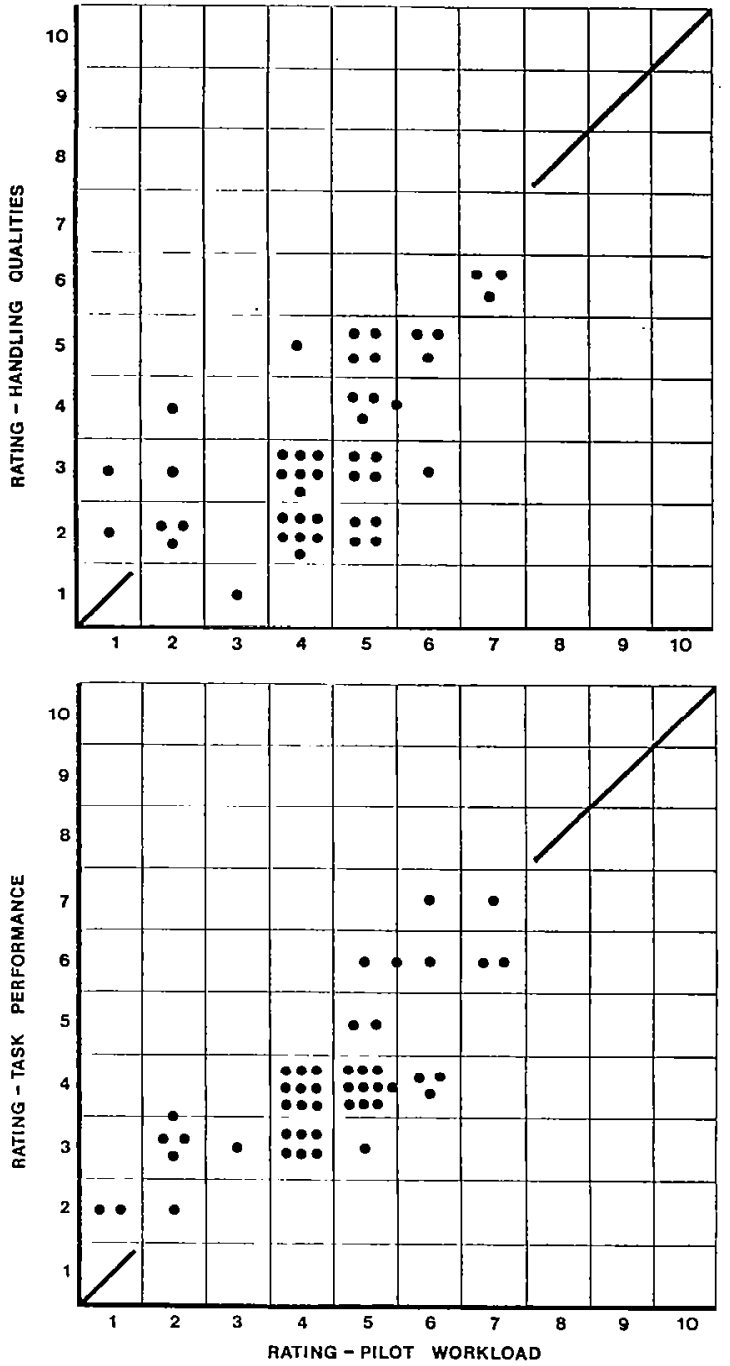

Fig. 7 Pilot ratings of dolphin tests

correlation between the ratings for the workload and the task performance. The pilot will give high ratings, if he doesn't come up to the wanted system performance in spite of high effort.

The information content of the signal data are summarized for each run by the statistical analysis. The run parameters are checked with a confidential test and averaged for each flight test. By correlating the statistical parameters with the ratings of the pilot's workload, the evaluation parameters arc determined. They are as follows for the dolphin tests:

1) Sum of the standard deviations of longitudinal and collective control inputs (control activity). 
2) Time integral of altitude over the obstacles (evaluation area). tude.

3) Peak-to-peak value of pitch atti-

4) Peak-to-peak value of acceleration in z-direction.

Table 3. Correlation of parameters with pilot ratings for workload

\begin{tabular}{lcccccc}
\hline $\begin{array}{l}\text { Evaluation } \\
\text { parameter }\end{array}$ & 1 & 2 & 3 & 4 & 5 & 6 \\
\hline $\begin{array}{l}\text { Evaluation } \\
\text { area }\end{array}$ & .72 & .11 & .60 & .56 & .79 & .63 \\
$\begin{array}{l}\text { Peak to peak } \\
\text { pitch attit. }\end{array}$ & .62 & .89 & .22 & .20 & .87 & .20 \\
$\begin{array}{l}\text { Peak to peak } \\
\text { z-acceler. }\end{array}$ & .57 & .78 & .74 & .86 & .96 & .84 \\
$\begin{array}{l}\text { Control } \\
\text { activity }\end{array}$ & .51 & .48 & .10 & .67 & .85 & .03 \\
\end{tabular}

Table 3 shows the correlation coefficients. Divergences exist between the pilots. The reasons for low correlation values are the pilot hasn't altered the parameter with speed and gross weight and/or the relationship between parameter and rating isn't Iinear.

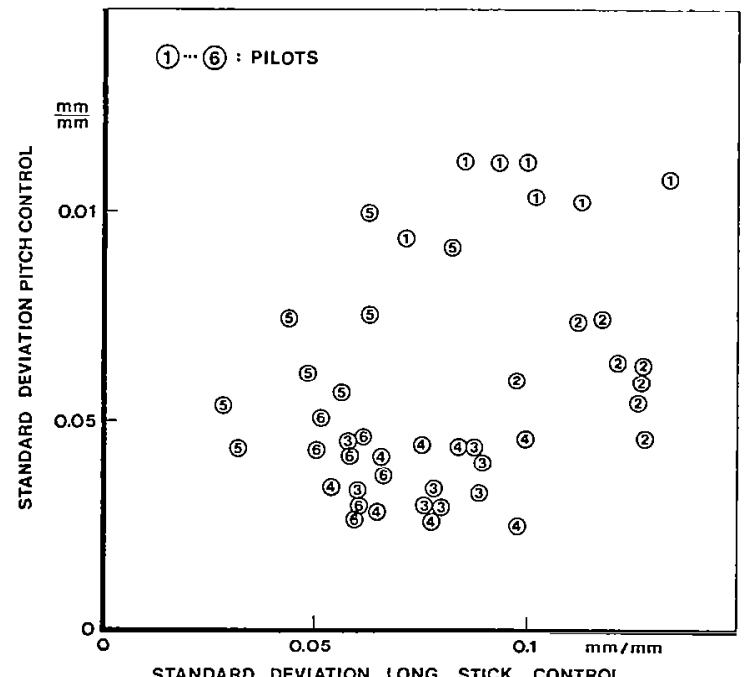

STANDARO DEVIATION LONG. STICK CONTROL

Fig. 8 Control strategies of pilots
Adapting the dolphin instructions, the pilots choose a control strategy characterized by a combination of the main controls longitudinal cyclic and collective. Deviations in state and position due to coupling are compensated with the other controls. Fig. 8 shows the control strategy depending on the pilot. Pilot 1 tends to a relative high activity in the collective, while pilot 2 flies the dolphin with high longitudinal control inputs for example. Fig. 9 points out the tendencies of standard deviations of controls with speed. The pilot's behaviour in the control strategy illustrates the broad spectrum of pilot adaptation.

The influence of the pilots also affects the resulting system performance. The levels of accelerations obtained in the tests have a linear dependency on the speed. The peak-to-peak of pitch attitude and the evaluation area parameter. includes the divergent weighting of the pilots for flying the dolphin. While some pilots keep the evaluation area constant this parameter increases with speed for the others. The pilots influence upon the pitch attitude values seems to be still higher. Depending on the pilot the attitude level increases, decreases or keeps constant.

The test results of all pilots can be summarized in the evaluation diagrams. The relation between the control activity and the evaluation area as the main task performance parameter is shown in Fig. 10. The pilot ratings describe clear tendencies for the defined evaluation scales. Accordingly evaluation boundaries are inscrtcd in the diagrams. The ratings deteriorates with increasing evaluation area and the pilots have experienced a higher workload. With area values over the additionally drawn boundary the pilots have substantiated their workload with minimizing the time and altitude over the obstacles. Relative to the control activity there exists an evaluation optimum. A relation between evaluation and the separated activity in the controls can't be constituted. The causes for the disorientation of some test results in Fig. 10 are due to the values of other parameters (see Fig. 11 and 12). With higher levels of pitch attitude the workload of the pilots increases, because high attitudes render more difficilt the orientation of the pilots in the course. The reasons for the relative good ratings of pitch levels higher than $40 \mathrm{deg}$ are high accelerations. Moreover the pilots mentioned acceleration levels over $1.6 \mathrm{~g}$ as a reason of their workload in the comments. But also lower accelerations influence the pilot ratings workload.

Summarizing the evaluation diagrams characteristics of the helicopter systems 


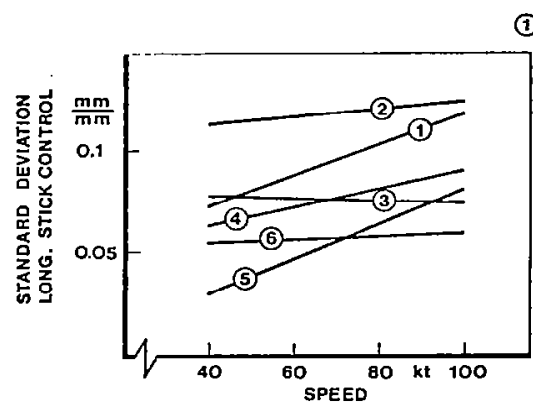

(1) -..(B) : PILOTS

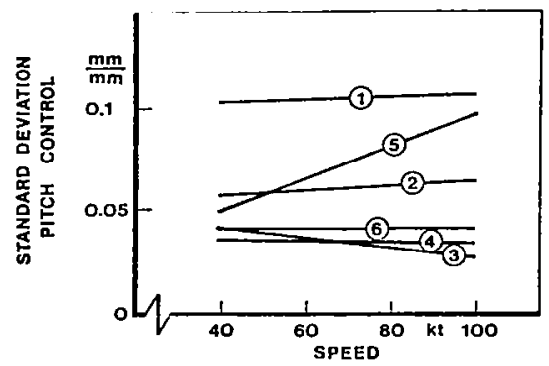

Fig. 9
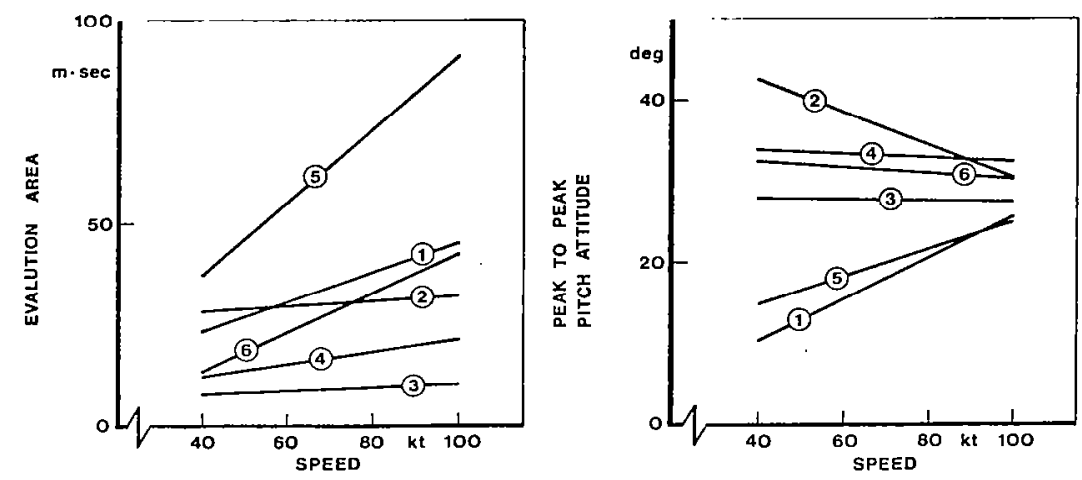

Tendencies of evaluation parameters

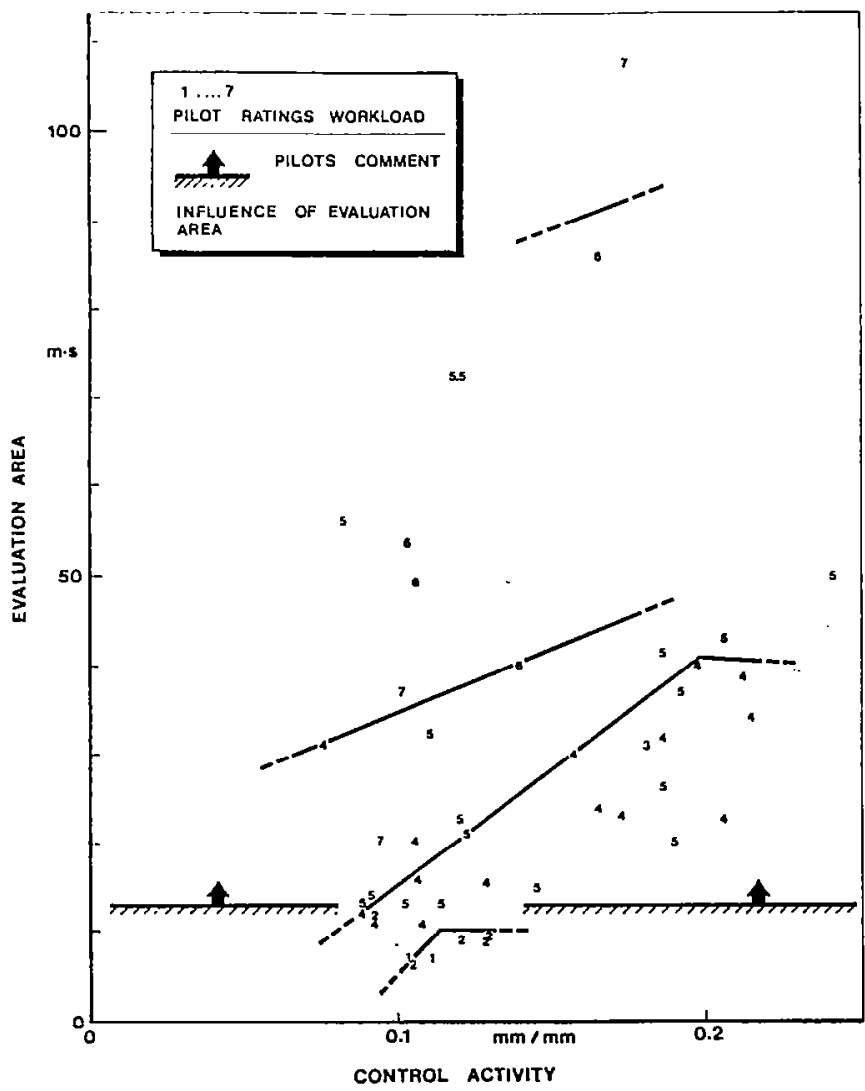

Fig. 10

Pilot rating trends with control activity and evaluation area 


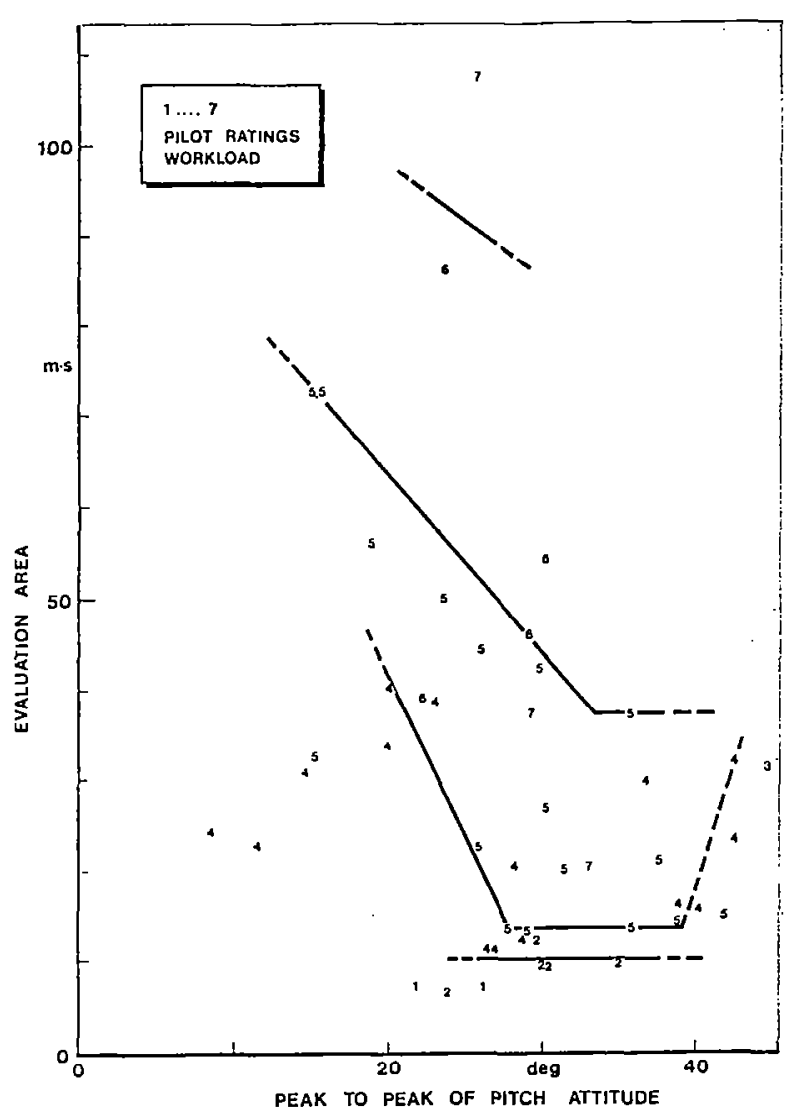

Fig. 11 Pilot rating trends with pitch attitude and evaluation area

can be recommended related to the flown task. Independent of the helicopter state, the fulfillment of the dolphin task should be possible for a satisfactory evaluation: 1) with low altitudes and short times above the obstacles (evaluation area lower than $3 \mathrm{~m} \cdot \mathrm{sec}), 2$ ) with a maximum level of $\mathrm{z}-$ acceleration of $\pm 0.45 \mathrm{~g}$, and 3 ) with a low level of pitch attitude. For the necessary control activity an optimum exists, but a separated influence of longitudinal cyclic and collective controls can't be achieved by the test resixts.

\section{Discussion of Control Strategy Results}

The objective of the additionally conducted control strategy tests is to assess the influence of different control combinations on the task performance in the dolphin. More than that the NOE-flying must give an answer to the question whether a moment control or a force control of helicopter offers the better technique to fly closely over obstacles. As mentioned above the task includes three control stra-

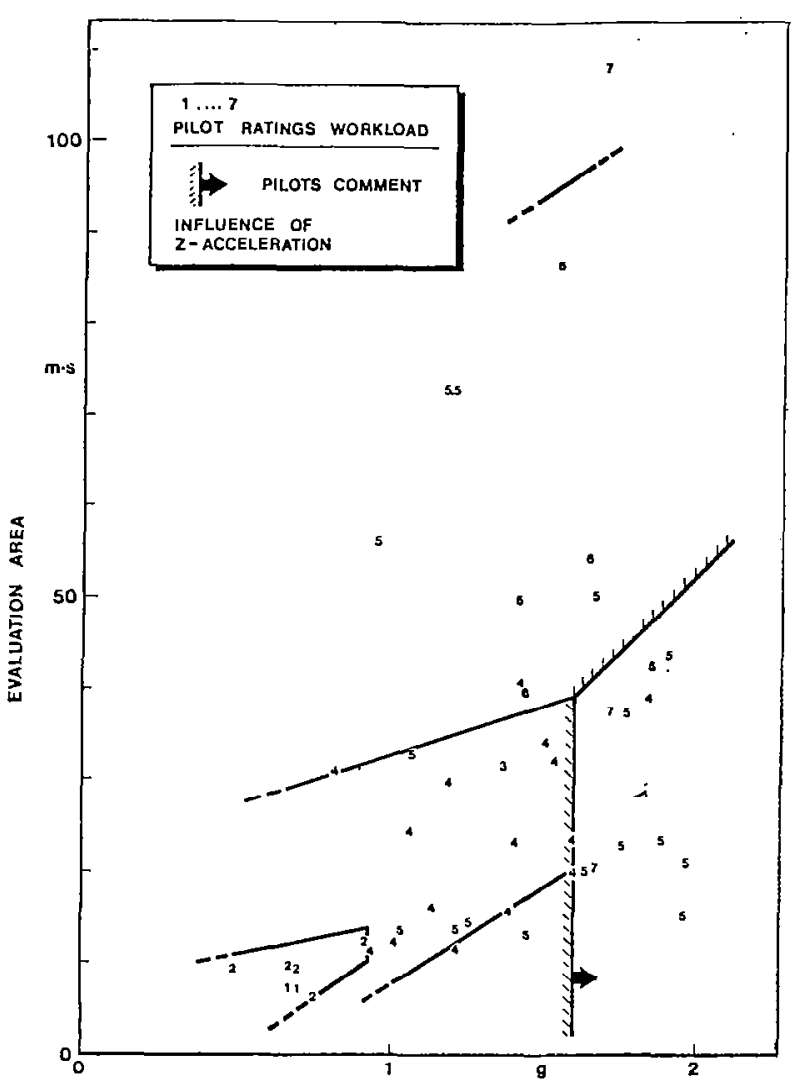

PEAK TO PEAK OF $z$-ACCELERATION

Fig. 12 Pilot rating trends with $z$-acceleration and evaluation area

tegies:

1) Combination of longitudinal stick and pitch control.

2) Stick control.

3) Primarily pitch control.

As an example Fig. 13 shows test data of the BO 105. The curves give an impression of the signal contents in amplitude and dynamics. The cross correlation of control and $\mathrm{a} / \mathrm{c}$ state signals is evident.

The realization of the defined strategies by the pilots is skeletonized in Fig. 14 and 15. All test configurations were feasible for the pilots and were accepted after sufficient time of exercise with the exception of the $110 \mathrm{kt}$ stick configuration of the UH-1D. When comparing the helicopters it was noted that in the UH-1D tests the pilots used higher collective inputs, especially for the stick configuration. The UH-1D requires a lower stick activity on account of the lower collective to pitch cross-coupling. For the BO 105 the coupling 


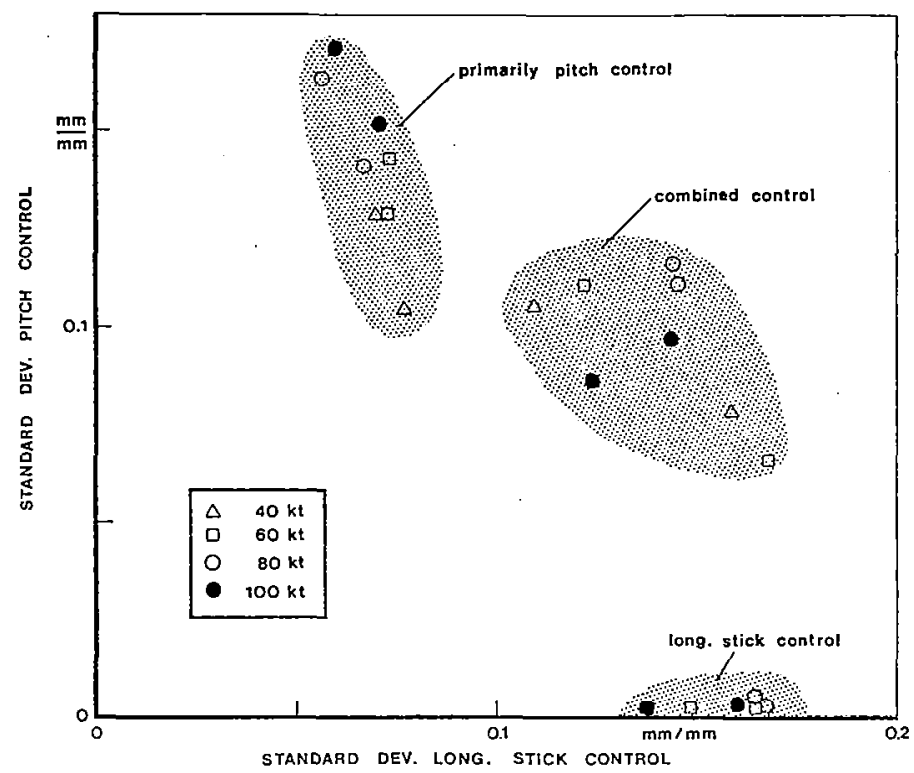

Fig. 15

Control strategy verification (UH-1D)

is nearly doubled with the speed from 40 to $100 \mathrm{kt}$. Two pilots tried to compensate this behaviour with appropiate longitudinal cyclic inputs.

To evaluate the achieved task performance the resulting parameters are drawn versus the ratio of the standard deviations for collective and longitudinal cyclic. Fig. 16 and 17 summarize the test results. All parameters show quite the same tendencies with increasing of control ratio except the deteriorating values of pitch attitude and evaluation area for extreme high pitch to stick control ratio for the BO 105 due to coupling.

To derive recommendations from these results for the helicopter system the dolphin task can be performed in a bctter way with emphasis on collective control that means direct force control consequently. Naturally a decrease of the colleciive to pitch cross-coupling is assumed. This can be mainly achieved by the design compromise of the rotor system or by additional feedback systems. Carrying out the dolphin task with high control moment capacity is not adequate, but produces relative higher values of attitude, acceleration, and evaluation area. For the application and adaptation of a direct force control additional studies including engine dynamics have to be performed.

\section{Conclusions}

A test and analysis technique has been developed at DFVLR and has been proven as a valuable tool for the evaluation of closed loop flying qualities with regard to

the mission. This technique has been applied to a dolphin task that is derived from the German Anti Tank Helicopter mission. From the test results the following general tendencies and conclusions are noted:

1) The described method leads to an acceptable assessment of task performance and control activity.

2) The combinations of the parameters yield flying qualities recommendations for helicopters related to the dolphin task.

3) The parameters for a quantitative evaluation are the evaluation area, the level of pitch attitude, the level of vertical acceleration, and the activity in longitudinal and collective control.

4) With emphasis on collective control (direct force control) the dolphin task can be performed in a better way. Therefore a low collective to pitch cross-coupling is necessary.

\section{References}

1. "Helicopter Flying and Ground Handling Qualities; General Requirements for Military Specification", MIL-H-8501 A, Sept. 1961.

2. Reichert, G., and Delker, P., "Handling Qualities with the Bolkow Rigid Rotor System", Paper No. 218 , American Helicopter Society $24 \mathrm{th}$ Annual Forum, Washington, D.C., May 1968.

3. "Flying Qualities of Piloted V/STOI Aircraft; Military Specification", MIL-F-83300, Dec. 1970. 

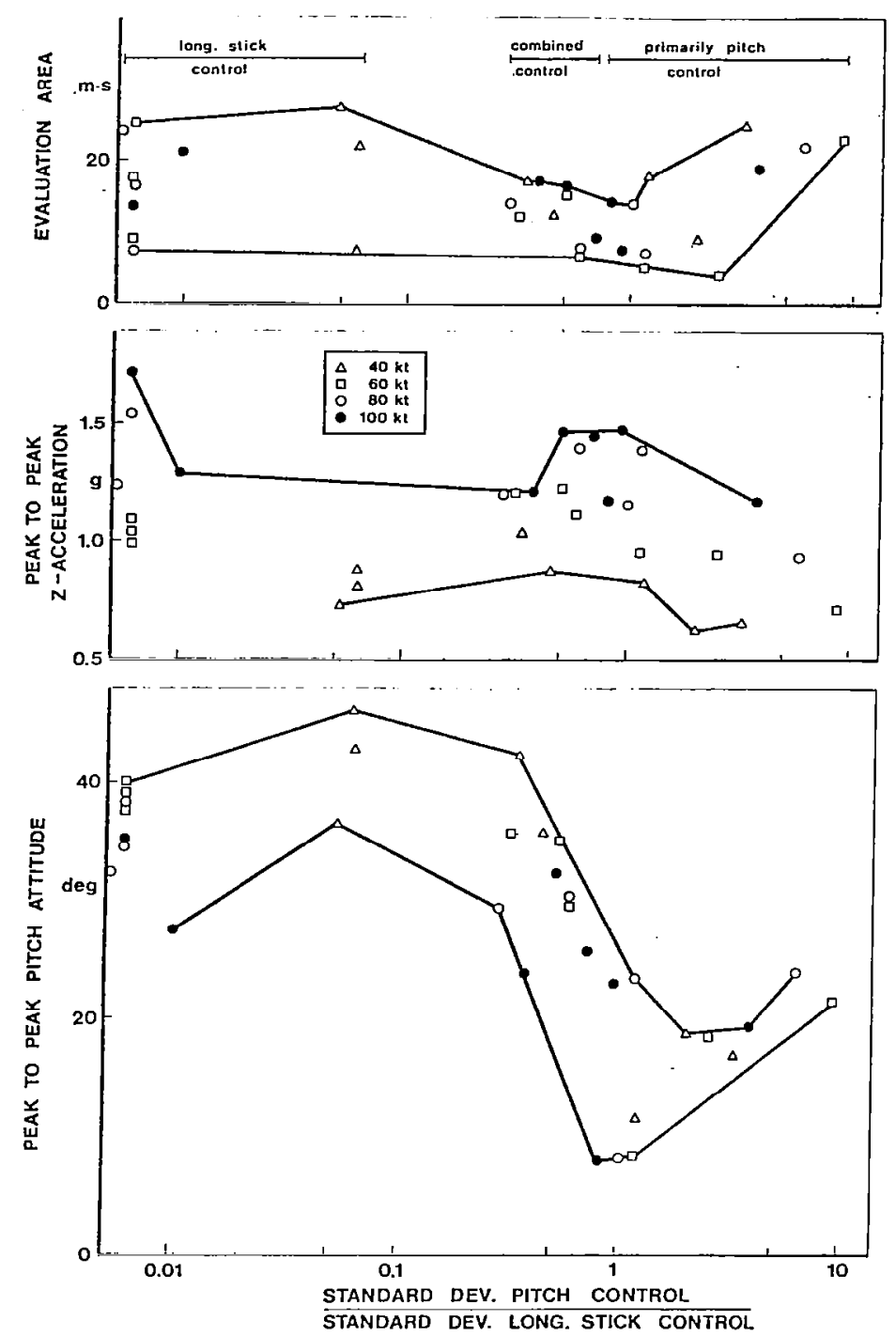

Fig. 16 Effect of control ratio on
evaluation parameters (BO 105) 

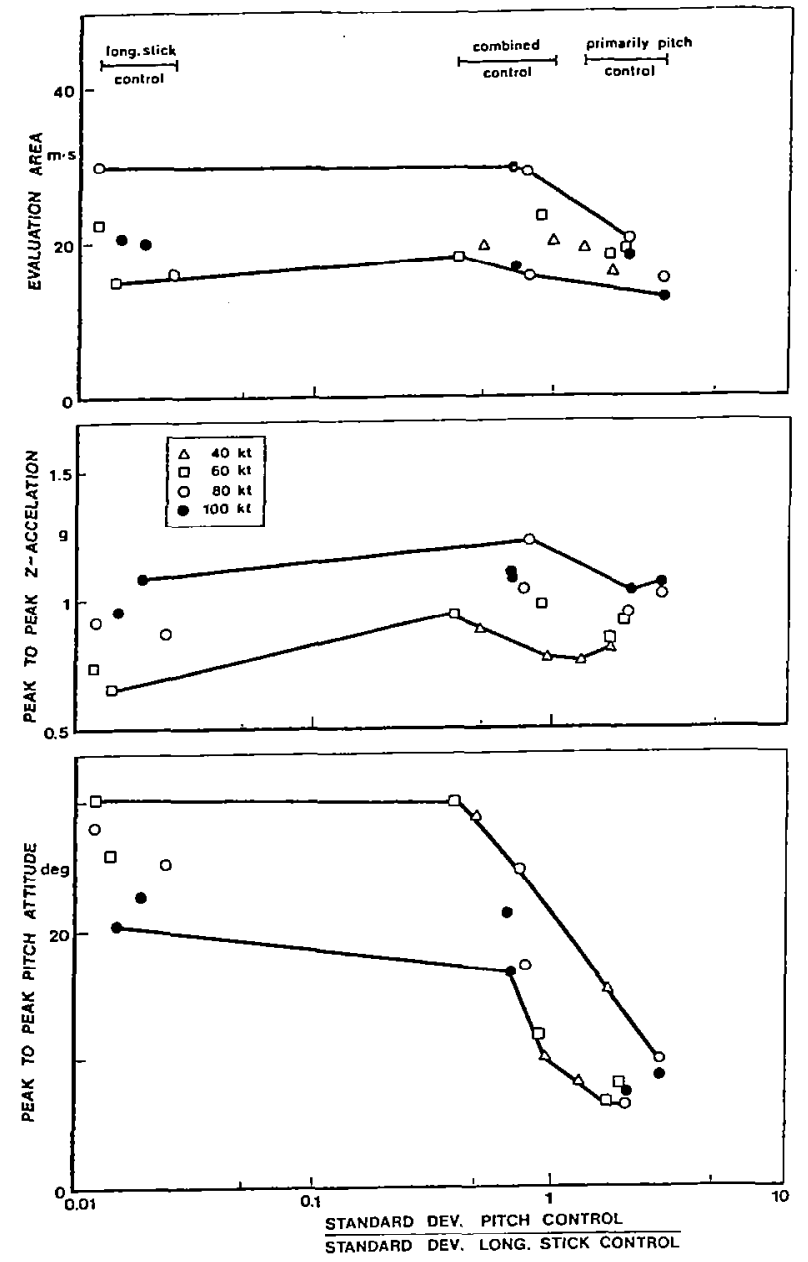

Fig. 17 Effect of control ratio on evaluation parameters (UH-1D)

4. Corliss, L.D., and Carico, G.D., "A Preliminary Flight Investigation of Cross-Coupling and Laleral Damping for Nap-of-the-Earth Helicopter Operations", Paper No.81-28, American Helicopter Society 37 th Annual Forum, New Orleans, La, May 1981.

5. Tomlinson, B.N., and Padfield, G.D., "Piloted Simulation Studies on Helicopter Agility", Paper No. 30, 5th European Rotorcraft and Powered Lift Aircraft Forum, Amsterdam, The Netherlands, Sept. 1979.

6. Pausder, H.-J., and Gmelin, B.L., "Flight Test Results for Task Oriented Flying Qualities Evaluation", Paper No. 80-29, American Helicopter Society 36 th Annual Forum, Washington, D.C., May 1980.
7. Cooper, G.E., and Harper, R.P., "The Use of Pilot Rating in the Evaluation of Aircraft Handing Qualities", AGARD Report No. 567, April 1969 .

8. Sanders, K., Pausder, H.-J., and Hummes, D., "Flight Tests and Stastistical Data Analysis for Flying Qualities Investigations", Paper No. 56, 6th European Rotorcraft and Powered Lift Aircraft Forum, Bristol, England, Sept. 1980.

9. Gmelin, B.I., and Pausder, H.-J. "The Impact of Helicopter Flight Mechanics on Mission Performance" AGARD-CP-313, Paris, France, Aprii 1981, pp. 15-1-15-14.

10. Karmann, R., "Programmable Multipurpose Flight Test Instrumentation System", AGARD-CP-299, Geilo, Norway, Oct. 1980, pp. 22-1-2213. 